\title{
Long-term alterations of cell population in the adult rat forebrain following the exposure to fractionated doses of ionizing radiation
}

\author{
Soňa Bálentová ${ }^{,}$Eva Hajtmanová ${ }^{2}$, Ivana Kinclováa ${ }^{2}$ Ján Lehotský ${ }^{3}$, Dušan Dobrota ${ }^{3}$ \\ and Marián Adamkov ${ }^{1}$ \\ ${ }^{1}$ Institute of Histology and Embryology, Jessenius Faculty of Medicine, Comenius University, Malá Hora 4, 03601 Martin, \\ Slovak Republic \\ ${ }^{2}$ Department of Radiotherapy and Oncology, Martin University Hospital, Kollárova 2, 03659 Martin, Slovak Republic \\ ${ }^{3}$ Institute of Medical Biochemistry, Jessenius Faculty of Medicine, Comenius University, Malá Hora 4, 03601 Martin, Slovak \\ Republic
}

\begin{abstract}
We investigated radiation-induced delayed alterations of proliferating population, cells undergoing apoptosis and glial cells housed rat brain neurogenic region. Adult male Wistar rats were investigated 30, 60 or 90 days after whole-body irradiation with fractionated doses of gamma rays (the total dose of 4 Gy). Using immunohistochemistry for detection of cell proliferation marker Ki-67, caspase 3 as apoptotic marker and GFAP for mature astrocytes we have been performed quantitative analysis in different forebrain's areas along the SVZ-OB axis, i.e. in the anterior subvetricular zone (SVZa), vertical arm, elbow and horizontal arm. In animals that survived thirty days after radiation treatment initial decrease of the Ki-67-positive cells was seen in regions along the SVZ-OB axis. The highest increase was observed in vertical arm on the 60th day followed by the most striking decline on the 90th day after irradiation. Cells undergoing apoptosis didn't showed expressive increase during entire experiment except of horizontal arm. The most striking changes of GFAP-positive cells were seen 30 and 60 days after irradiation in vertical arm and elbow. Results suggested that radiation response of proliferating cells and astrocytes resides the SVZa may play contributory role in development of more adverse radiation-induced late effects.
\end{abstract}

Key words: Ionizing radiation - SVZ-OB axis - Cell proliferation - Apoptosis - Astrocytes

\begin{abstract}
Abbreviations: BSA, bovine serum albumin; GFAP, glial fibrillary acid protein; ICAM-1, intercellular adhesion molecule-1; LV, lateral ventricle; OB, olfactory bulb; PBS, phosphate buffer saline; RMS, rostral migratory stream; SGZ, subgranular zone; SVZ, subventricular zone; SVZa, anterior horn of the SVZ; TNF- $\alpha$, tumor necrosis factor- $\alpha$.
\end{abstract}

\section{Introduction}

The adult mammalian brain contains at least two discrete regions with persistent mitotic activity. The first region is known as the subventricular zone (SVZ), lining the brain lateral ventricles (LV) and the second one is the subgranular zone (SGZ) in the dentate gyrus of hippocampal formation (Doetsch et al.

Correspondence to: Soňa Bálentová, Institute of Histology and Embryology, Jessenius Faculty of Medicine in Martin, Comenius University, Malá Hora 4, 03601 Martin, Slovak Republic E-mail: balentova@jfmed.uniba.sk
1997; Kempermann 2002). The fate of descendants of proliferating cells depends on their location. The SVZ progenitors migrate along the well defined pathway, called the rostral migratory stream (RMS) towards to olfactory bulb (OB) where they differentiate into granule or periglomerular interneurons and integrate to preexisting functional circuits (Carleton et al. 2003; Abrous et al. 2005; Lledo et al. 2006). Process of continual cell turnover in neurogenic regions is closely accompanied by elimination of newlyborn cells through programmed cell death. Studies in rodents revealed that certain numbers of cells undergo apoptotic cell death during the early postnatal age as well as in adulthood (Brunjes and Armstrong 1996; 
Thomaidou et al. 1997; Biebel et al. 2000). The effects of ionizing radiation on the brain can result in significant injury to normal brain structures. Research into irradiation effects in normal brain tissue has been mostly focused on studies of single-dose irradiation (Peissner et al. 1999; Amano et al. 2002; Mizumatsu et al. 2003; Lazarini et al. 2009). Single moderate (2-10 Gy) whole brain irradiation led to substantial loss of proliferating cells and immature neurons from the SVZ in a dose-dependent fashion up to several months after treatment, however, surviving cells have limited potential of SVZ repopulation or regeneration (Tada et al. 1999; Amano et al. 2002). Furthermore, single local irradiation with wide range of higher radiation doses $(30,50,75,120 \mathrm{~Gy})$ of rat brain result in time-dependent and dose-dependent increase of vascular permeability, changes in astrocytic morphology and enhanced radiation necrosis founded several months after treatment (Münter et al.1999; Kamiryo et al. 2005). Large single doses of radiation are not commonly used in clinical treatment. The leading mode of radiation delivery in humans is fractionated radiotherapy. The influence of dose, fractionation treatment, time of irradiation on late functional and histopathological changes have been derived from studies in rodents. Shinohara et al. (1997) in rat model demonstrated that after daily administration of $1.5 \mathrm{~Gy}$ fractions, the first three fractions increased the apoptosis and the rest of admistered fractions have no effect on decrease of cell population. There has been reported that fractionated treatment led to increased blood-brain barrier permeability, enhanced expression of astrocytes and high expression of inflammmation-related molecules (intercellular adhesion molecule-1 (ICAM-1), tumor necrosis factor- $\alpha$ (TNF- $\alpha)$ ) up to six months post-irradiation (Cicciarello et al. 1996; Gaber et al. 2003; Yuan et al. 2006).

In the present study we investigated the alteration in spatio-temporal distribution of proliferating population, cells undergoing apoptosis and glial cells of adult rats, exposed to fractionated doses (the total dose of $4 \mathrm{~Gy}$ ) of gamma rays at various intervals after post-irradiation survival.

\section{Materials and Methods}

\section{Animals}

Adult male rats of the Wistar strain (bred in Dobrá Voda, Slovak Republic) 7-8 months old at the beginning of experiment and weighing approximately $380 \mathrm{~g}$ were used in this study. The animals were kept under standard conditions (temperature of $22-24^{\circ} \mathrm{C}$, light-controlled enviroment with $12 / 12 \mathrm{~h}$ light/dark cycle) and provided with food and water ad libitum. The methods for animals use were approved by the Animal Care and Use Committee, Jessenius Faculty of Medicine in Martin, Comenius University, Slovak Republic (approval number RO 1663/08-221/3 for animal experiments).

\section{Irradiation}

For irradiation procedure the animals were anaesthetized by i.p. injection of ketamine ( $1-2 \mathrm{ml} / \mathrm{kg}$ body weight) and a subcutaneous injection of xylasine (0.1-0.2 $\mathrm{ml} / \mathrm{kg}$ b.w.). The rats were whole-body irradiated using a ${ }^{60} \mathrm{Co}$ radiation source (apparatus Teragam02 UJP Prague, Czech Republic). The total radiation dose administered was $4 \mathrm{~Gy}$ of gamma rays $(1 \mathrm{~Gy} \times 4)$ given at seven days intervals and the animals survived 30, 60 or 90 days after the last exposure (Irr-30, Irr60 , Irr-90, respectively; three animals at each time interval). Control animals were killed 30 days $(n=3), 60$ days $(n=3)$ or 90 days $(n=2)$ after sham irradiation.

\section{Immunohistochemistry}

Thirty to ninety days after irradiation, the animals were overdosed by inhalation of mixture 3\% sevoflurane, $68 \%$ $\mathrm{N}_{2} \mathrm{O}$ and $30 \% \mathrm{O}_{2}$ and transcardially perfused with saline followed by fixative $4 \%$ paraformaldehyde in $0.1 \mathrm{M}$ phosphate buffer (PB). Brains were immediately removed from the skull, postfixed overnight in the same fixative at $4^{\circ} \mathrm{C}$ and cryoprotected in $30 \%$ sucrose for $18 \mathrm{~h}$. Serial sagittal $30 \mu \mathrm{m}$ sections were cut on cryostat, collected on lysine-coated slides and air-dried. To minimize nonspecific binding of the secondary antibody, sections were incubated for $1 \mathrm{~h}$ at room temperature in goat blocking solution (10\% goat serum, $1 \%$ bovine serum albumin (BSA), 0.5\% Tween 20 in phosphate buffer saline (PBS) ) and then covered overnight at $4^{\circ} \mathrm{C}$ by rabbit anti-Ki-67 (Abcam, Cambridge, UK), a nuclear antigen that is expressed during the entire cell cycle except $\mathrm{G}_{0}$ stage, rabbit anti-glial fibrillary acid protein (GFAP; 1:50, Chemicon, Temecula, CA, USA), selective marker for astrocytes and mouse anti-caspase 3 (1:50, Santa Cruz Biotechnology, CA, USA) an enzyme involved in the activation cascade of caspases responsible for apoptosis execution. After rinsing the sections were incubated for $2 \mathrm{~h}$ at room temperature with goat anti-rabbit secondary antibody labeled with Alexa Fluor 488 (1:100, diluted in 0.3\% Triton X-100 and 1\% BSA in PBS, Molecular Probes, Eugene, OR, USA) and finally coverslipped with Fluoromount (Serva, Germany). The slides were viewed with a confocal laser scanning microscope Olympus FluoView FV10i (Olympus, Japan) with $10 \times$ objective, equipped with Alexa Fluor 488 (excitation: $499 \mathrm{~nm}$; emission: $520 \mathrm{~nm}$ ). The image capturing was performed with an Olympus Fluoview FV10-ASW software, version 02.01 (Olympus).

\section{Image analysis}

Quantitative assessment was performed in standardized counting area which included $30 \mu \mathrm{m}$ thick serial sagittal sections from four different areas along the SVZ-OB axis i.e. 
the anterior horn of the SVZ (SVZa) and vertical arm, elbow, horizontal arm representing the individual parts of RMS (Fig. 1). The vertical arm of the RMS begin in SVZa of brain LVs and curved ventrally between the corpus callosum and striatum. Then the RMS turned in a prominent angle, the elbow located half of the distance from the rostral tip of LV to the OB and the horizontal arm, which presents the rostral half of the RMS. The numbers of positive fluorescent labelled cells (green fluorescent) were counted in each stained section with entire extent of the RMS (10-15 sections per animal) and the cell density was quantified at a magnification of $\times 10$. Counting was performed by ImageJ (NIH, Bethesda, MD, USA) a public domain image processing and analysis program and Commands in "Analyze" menu counts and measures objects in thresholded images to distinguish the object from the background. Once the image has been tresholded, they can then be analysed. The menu command "Analyze/Analyze particles" can be used to obtain various information regarding particle size and numbers. Finally, the results were displayed as the total numbers of positively labelled cells per $\mathrm{cm}^{2}$.

\section{Statistical analysis}

Data was analyzed using ANOVA one-way analysis followed by a Tukey-Kramer test comparison and presented as mean \pm standard error (S.E.M). Statistical significance was set at $p \leq 0.05$.

\section{Results}

Quantitative image analysis of sagittal sections in the rat's forebrain showed different pattern of density between control individuals and irradiated ones as well as among radiation-treated animals (Figs. 2, 3). In every group was observed decrease of cell proliferation according a caudorostral gradient with maximum cell density in initial parts and minimal cell distribution in caudal parts of the RMS (Fig. 4). In control animals was seen the highest distribution of proliferating cells in the SVZa $\left(22.75 \pm 7.02 / \mathrm{cm}^{2}\right)$ and in the elbow $(51.25 \pm 14.61)$, no cells has been found in horizontal arm of the RMS. Thirty days after fractionated treatment was observed slight decline in cell density along the migratory pathway and virtually no change has been observed in initial SVZa $(23 \pm 7.35)$. In animals, survived sixty days after irradiation was found the highest increase of the numbers of Ki-67-positive cells (Ki-67 ${ }^{+}$cells) in the vertical arm (Irr-60: $80.2 \pm 26.3$ versus Irr-30: $13.8 \pm 8.95$; $p \leq 0.05)$, no change was observed in other counted parts. Contrary to this findings, in the following group, survived ninety days after radiation treatment was seen the strongest decrease in the vertical arm (Irr-90: $5 \pm 3$ vs. $35.67 \pm$ 14.17; $p \leq 0.01$ ), however, the other counted parts along the migratory pathway didn't undergo expressive changes in the rate of proliferation.

The rate of radiation-induced apoptosis didn't undergo significant changes in course of ninety days after irradiation (Fig. 5). More expressive increase was observed along the SVZ-OB axis of animals, investigated sixty and ninety days after fractionated treatment. The numbers of caspase3-positive cells (caspase $3^{+}$cells) were peaked in the vertical arm (Irr-60: $26.33 \pm 6.33$ vs. Irr-90: $24.33 \pm 5.81$ vs. C: $9.25 \pm 2.5$ ) and after that slowly decreased similarly to control values in elbow (Irr-60: $19.33 \pm 10.71$ vs. Irr-90: $19.33 \pm 4.09$ vs. C: $18.67 \pm 8.67)$ and horizontal arm (Irr-60: $10.33 \pm 6.74 v s$. Irr-90: $15 \pm 10.41 v s$. C: $3 \pm 2.5$ ). Population of astrocytes that reside within the migratory pathway showed remarkable changes during investigation (Figs. 3,6). The most striking changes were seen thirty days after radiation treatment. The numbers of GFAP-positive cells (GFAP ${ }^{+}$cells) were gradually increased until reaching the elbow (Irr-30: 625.67 \pm 85.54 vs. C: $86 \pm 45.36$; $p \leq 0.001)$. In horizontal arm was found massive distribution (Irr-30: $456 \pm 28.02$ vs. C: no GFAP ${ }^{+}$ cells) and surpassed the values observed in initial SVZa (Irr30: $158.33 \pm 39.2 v s$. C: $143.33 \pm 75.65)$. Radiation response curve along the SVZ-OB axis was less strong in animals survived sixty days after exposure with maximum in elbow (Irr-60: $554.67 \pm 14.74$ vs. C: $86 \pm 45.36$; $p \leq 0.01$ ). However, in horizontal arm the numbers of GFAP-positive astrocytes decreased, the cell density was still higher then in previous radiation-treated group (Irr-60: $486 \pm 33.08$ vs. Irr-30: $456 \pm 28.02)$. Moderate changes have been found in group, survived ninety days post-irradiation. Enhanced values in initial SVZa (335.33 \pm 71.91$)$ were followed by temporary decrease and after repeated increase in the elbow were replaced by secondary decline in rostral part of the SVZ-OB axis (248.75 \pm 33.09$)$.

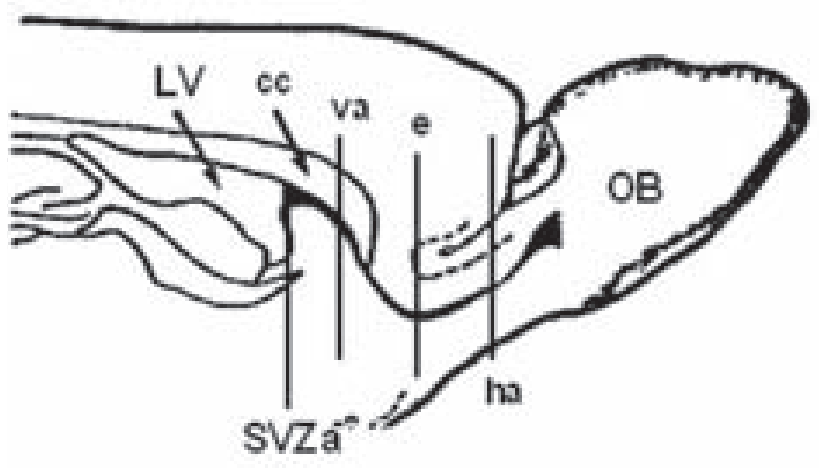

Figure 1. Schematic sagittal view of the rat forebrain. Vertical lines point the individuals parts along the SVZ-OB axis, where the cells were counted. e, elbow; cc, corpus callosum; ha, horizontal arm of the RMS; LV, lateral ventricle; OB, olfactory bulb; SVZa, anterior horn of the subvetricular zone; va, vertical arm. 

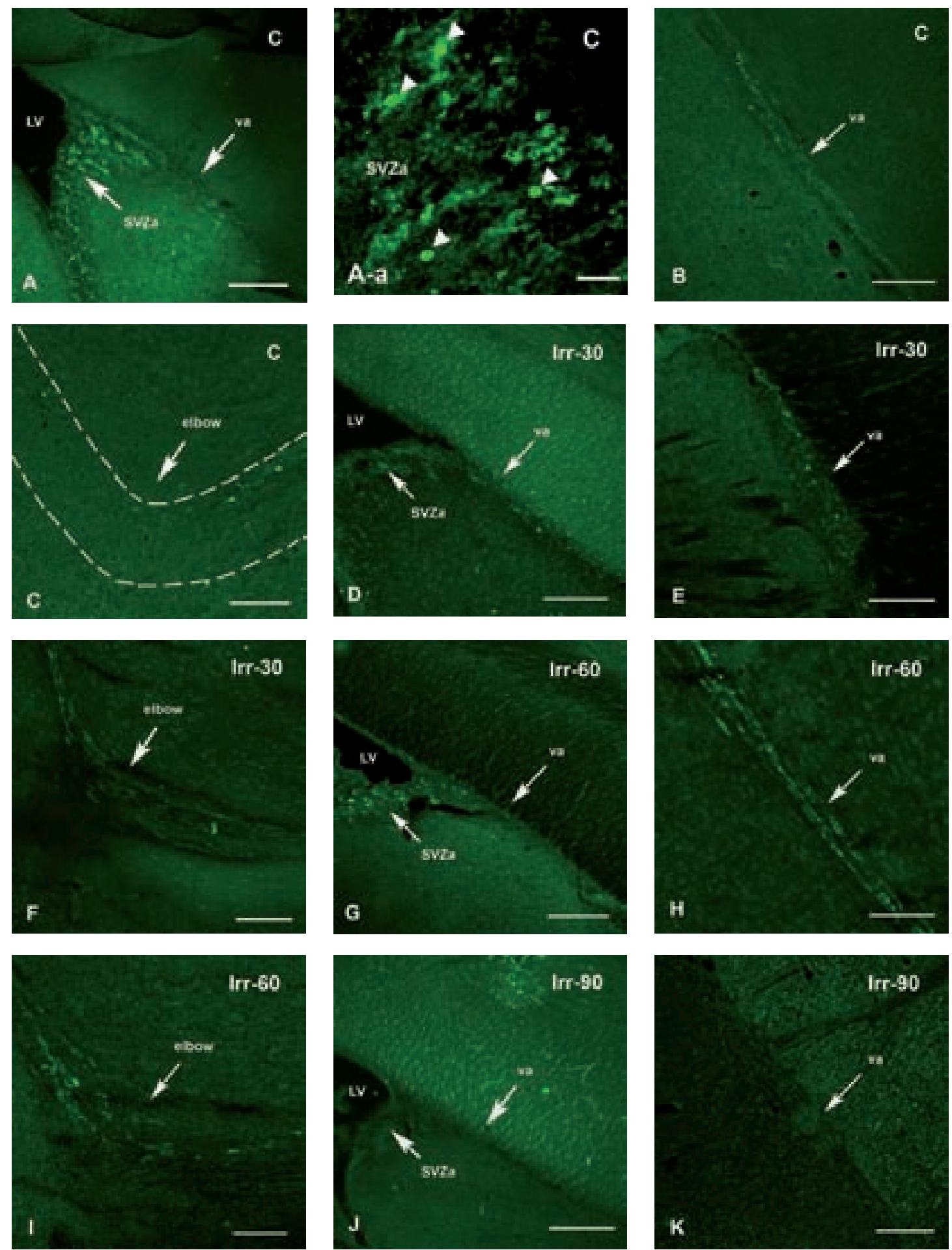

Figure 2. Ki-67 immunohistochemistry. Microphotographs of the sagittal sections through the forebrain of control animals and rats, survived 30, 60 and 90 days after fractionated radiation treatment (Control, Irr-30, Irr-60, Irr-90) showing the individual parts along the SVZ-OB axis, i.e. SVZa (A, D, G, J; arrows), vertical arm (B, E, H, K; arrows) and elbow (C; arrow, dashed lines, F, I; arrows) of the RMS. Subsequent decrease of proliferative activity detected by using Ki-67, (nuclear antigen that is expressed during the entire cell cycle except $\mathrm{G}_{0}$ stage) in course of experiment mostly visible in the SVZa and less in elbow. The most striking dynamic in cell proliferation was seen in vertical arm. (A-a) Detail of green fluorescent nuclei of Ki- $67^{+}$cells in the SVZa of control forebrain (arrowheads). SVZa, anterior horn of the subventricular zone; LV, lateral ventricle; va, vertical arm. Calibration bars: A-D, F-G, I-K $200 \mu \mathrm{m}$; E, H $100 \mu \mathrm{m}$; A-a $50 \mu \mathrm{m}$. 

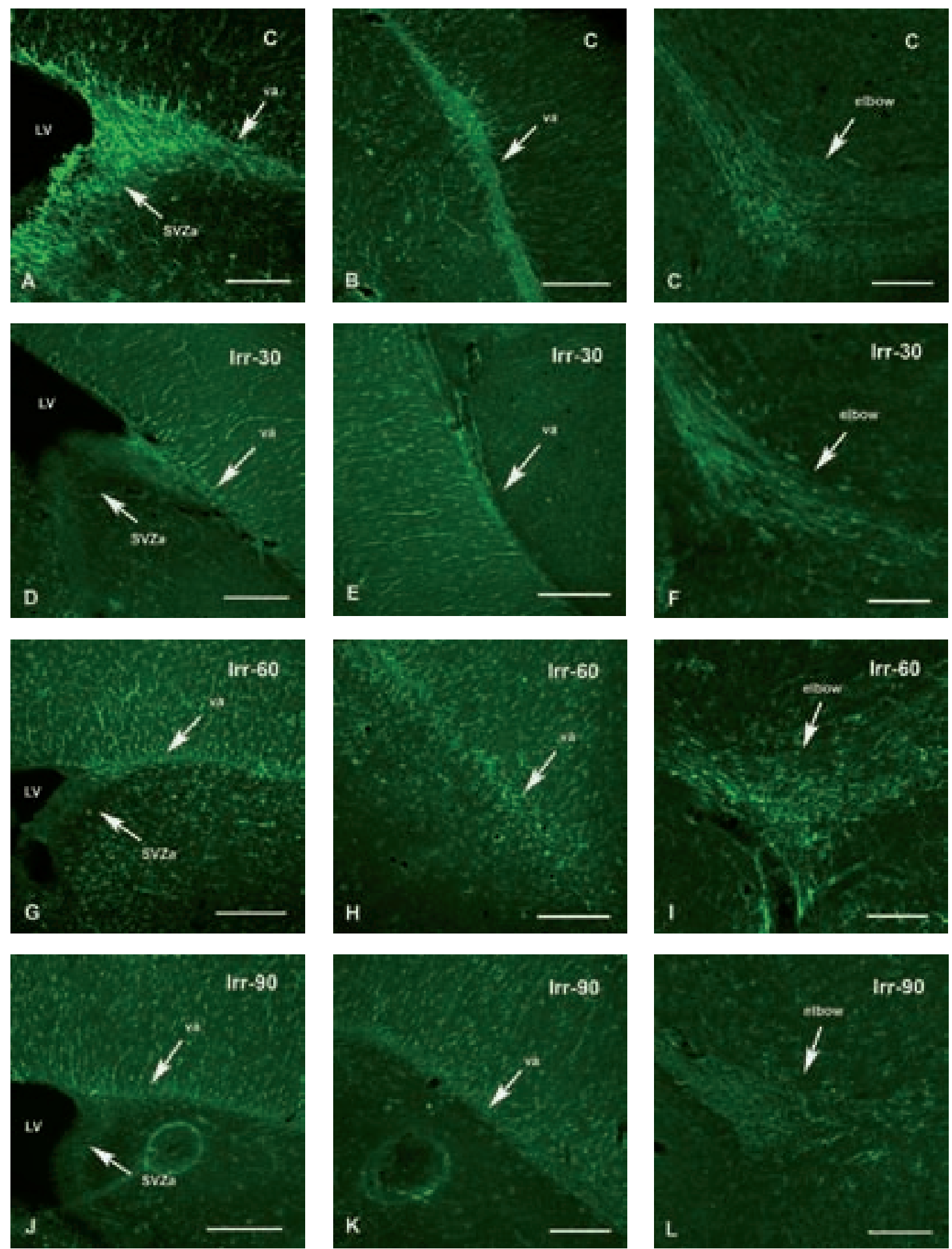

Figure 3. GFAP immunohistochemistry. Microphotographs of the sagittal sections through the forebrain of control animals and rats, survived 30, 60 and 90 days after fractionated radiation treatment (Control, Irr-30, Irr-60, Irr-90) showing the individual parts along the SVZ-OB axis, i.e. SVZa (A, D, G, J; arrows), vertical arm (B, E, H, K; arrows) and elbow (C, F, I, L; arrows) of the RMS. Similar post-irradiation dynamic in distribution of astrocytes immunostained with glial fibrillary acid protein (GFAP; intermediate filament protein present in differentiated and mature astrocytes) in all counted parts up to ninety days after irradiation. The most striking increase of GFAP ${ }^{+}$ cells was observed in elbow thirty days after irradiation following by slight decline up to ninety days after treatment. SVZa, anterior horn of the subventricular zone; LV, lateral ventricle; va, vertical arm. Calibration bars: A, C, F, I, L 100 m; B, D, E, G, H, J, K $200 \mu \mathrm{m}$. 


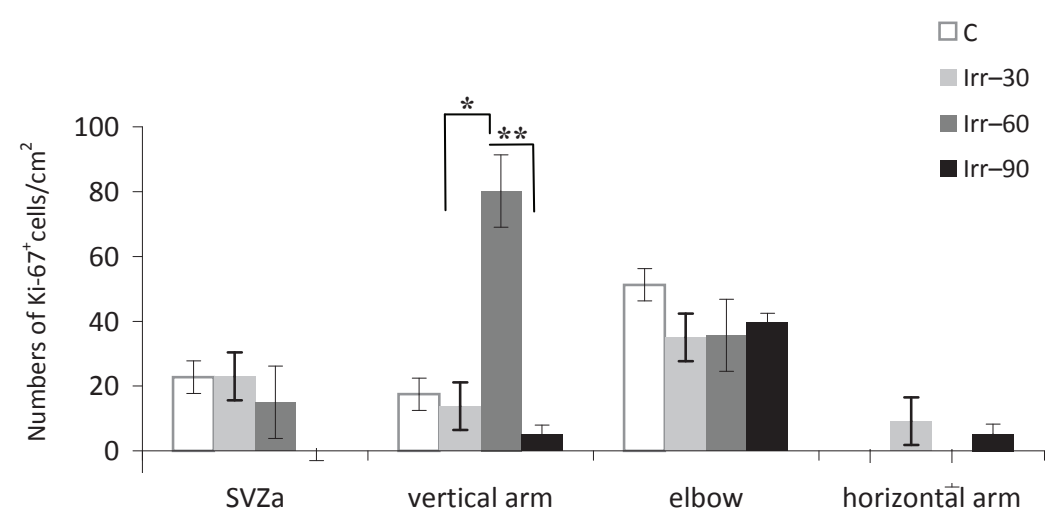

Figure 4. Distribution of proliferating cells in individual parts along the SVZ-OB axis in the forebrain of control animals and rats, survived 30, 60 and 90 days after fractionated radiation treatment (C, Irr-30, Irr-60, Irr-90; $\bar{x} \pm$ SEM). Statistical significance of differences between Irr-30 and Irr-60: ${ }^{*} p \leq 0.05$ and between Irr-60 and Irr-90: ${ }^{* *} p \leq 0.01$. For abbreviations see Fig. 1.

\section{Discussion}

In the present study, fluorescence microscopy examination of sagittal sections through the forebrain of rats, investigated thirty, sixty and ninety days after fractionated radiation treatment (total dose of $4 \mathrm{~Gy}$ ) revealed different pattern of cell density between control group and irradiated ones. During the entire experiment, proliferative activity decreased along the caudo-rostral gradient with the highest distribution in SVZa and the lowest in the horizontal arm. This finding is consistent with results published in our previous works (Bálentová et al. 2006, 2007) dealed with radiation-induced alterations in proliferation dynamics of cells, along the RMS, labeled with exogenous proliferative marker 5-bromo-2'deoxyuridine (BrdU). Investigation in course of eighty days after single exposure showed that after initial steep decline in all counted parts followed short-term increase in caudal parts of the RMS and subsequent decrease close to control values at the end of experiment. Despite this similarity, we found discrepancy between our findings and data published before. Initial SVZa didn't undergo profound changes during the experiment, except of animals, investigated ninety days after treatment. More expressive changes were seen in the vertical arm and the elbow, and few or virtually no proliferating cells were found in the horizontal arm. In another set of experiments we performed detection of fragmented DNA using terminaldeoxynukleotidyl tranferase-mediated dUTP-biotin nick end labeling (TUNEL) method and we found radiation-induced increased rate of apoptosis in course of ten days after irradiation (Bálentová et al. 2011). Taking into account these previous data, our simultaneous assessment of proliferating and apoptotic cells showed that proliferation activity surpassed a rate of apoptosis except of the most distant region along the SVZ-OB axis. However, in the latest post-irradiation interval proliferating population were diminished and a level of apoptosis was higher than

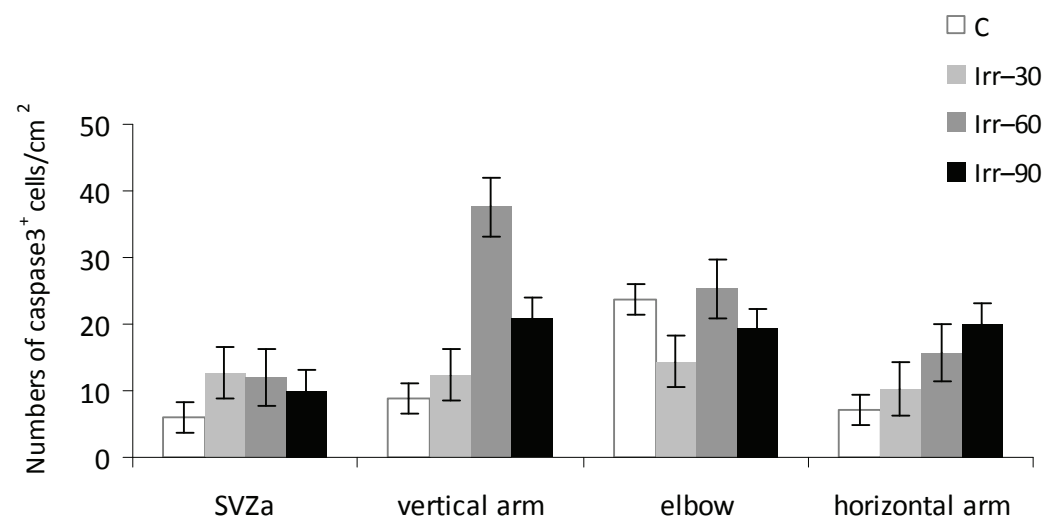

Figure 5. Distribution of apoptotic cells in individual parts along the SVZ-OB axis in the forebrain of control animals and rats, survived 30, 60 and 90 days after fractionated radiation treatment (C, Irr-30, Irr-60, Irr-90; $\bar{x} \pm$ SEM). For abbreviations see Fig. 1. 
in the rest of groups. The reason of such different radiation response between previous experiment and current results depends not only on different technique of radiation delivery. Important role played applied markers represented appropriate status of apoptotic pathway. Effector caspase 3 is responsible for the organized destruction of the cell in final stage of apoptosis. This executive protein is involved in activation and cleavage of other members of the caspase family and this event occur prior to nuclear DNA fragmentation. We suppose that identification of apoptotic cells in situ via specific labeling of nuclear DNA fragments displayed more unambiguous cell immunoreactivity.

There has been known that single and fractionated treatment induce different time-related and spatial related responses. Single moderate whole brain irradiation led to impaired numbers of proliferating cells and immature neurons arisen from the SVZ in a dose-dependent fashion up to several months after treatment, however, these changes were reversible (Tada et al. 1999; Amano et al. 2002). The proliferative response after depletion of cells through the apoptosis may represent the recruitment of a relatively quiescent stem cell population and this cellular input was seen after fractionated radiation treatment. Cellular response to fractionated and single-dose treatment is different; the single dose response is rapid, whereas the fractionated response is delayed and surpassed the post-radiation treatment (Gaber et al. 2003). On the other hand, cells stimulated to proliferate might express latent DNA damage which should be transmitted through the somatic or meiotic cell divisions to their progeny and may manifested in increased risk of mutagenesis and carcinogenesis (Dubrova et al. 1998; Little
2000; Vasilyeva et al. 2001; Smith et al. 2003; Bálentová et al. 2008).

The molecular characteristics of the tissue response to irradiation will be impacted by many endogenous and exogenous factors and it is often not clear how important the changes that are being observed are and what their spatial and temporal dependence is. Although initial radiation injury is often diffuse, late lesions often present focally and may progress. They may result from local infiltration of inflammatory cells, endothelial cell damage or dysregulated interaction between distinct cell types. In clinical radiotherapy, limited radiation tolerance of patients with intracranial lesions result in developing late delayed effects on surrounding parenchyma manifesting as cognitive impairments, which include demyelization, reactive astrogliosis, necrosis of white matter and varying degrees of vascular changes in both white and gray matter (Wong and Van der Kogel 2004).

Experiments done before showing that neuronal precursors are more sensitive to radiation then glial precursors (Tada et al. 1999; Mizumatsu el al. 2003). Snyder et al. (2005) reported that after irradiaton with $10 \mathrm{~Gy}$ dose the neuronal precursors expressing doublecortin (DCX) where almost completely eliminated, but the undifferentiated cells and glial precursors were spared. However, the cellular composition of adult rodent SVZa and the following RMS has been well established (Doetsch et al. 1997). The SVZa is organised around chains of neuroblasts or young neurons ensheathed by glial cells and other type of proliferating pluripotent precursors, which may generate both glia and neurons. The organisation of the RMS is similar, except of presence of precursors of cell lineages.

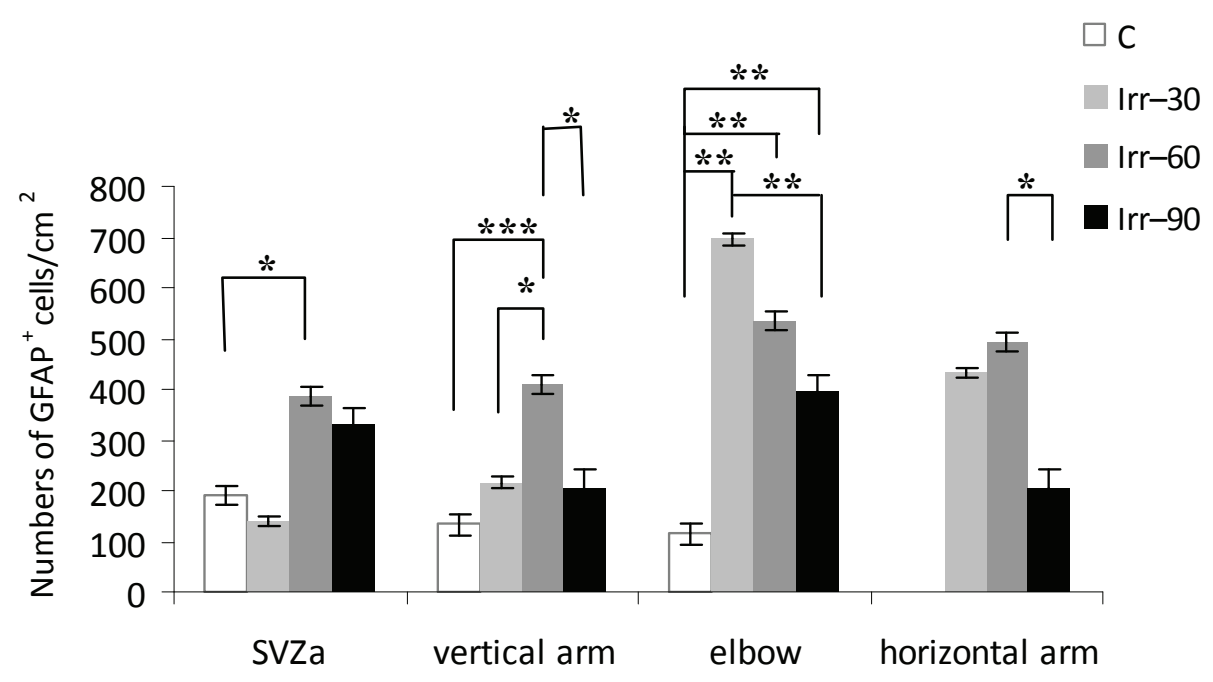

Figure 6. Distribution of astrocytes in individual parts along the SVZ-OB axis in the forebrain of control animals and rats, survived 30 , 60 and 90 days after fractionated radiation treatment (C, Irr-30, Irr-60, Irr-90; $\bar{x} \pm$ SEM). Statistical significance of differences between control and irradiated group and between the irradiated animals: ${ }^{\star} p \leq 0.005 ;{ }^{* *} p \leq 0,01 ;{ }^{* *} p \leq 0.001$. For abbreviations see Fig. 1 . 
In our experiment we found clear impact of fractionated irradiation on the population of astrocytes resides along SVZ-OB axis. Enhanced distribution of astrocytes was dominated up to sixty days after treatment mostly in rostral part of the RMS and at the end of experiment was lower, however still surpassed control values. Brain lesions generally increase SVZ neurogenesis or gliogenesis and cause SVZ cell emigration to ectopic locations (SundholmPeters et al. 2005). Regarding to glial cell fate after radiation treatment, radiation injury can preserve production of glial progenitor cells, however the radiosensitivity seems to be dependent on cell type. Previous studies reported about higher radiosensitivity of oligodendrocytes and astrocytes appeared to be relative resistent (Sano et al. 1997; Chow et al. 2000; Kurita et al. 2001; Mizumatsu et al. 2003). Recently, we have been published data from concurrent study dealed with radiation-induced alterations in distribution of proliferating and glial cells in selected hippocampal regions (Bálentová et al. 2012). Since we were not concerned with neurogenic SGZ of dentate gyrus, immunohistochemical labeling for Ki-67 and GFAP in two subregions, cornu ammonis region 1 (CA1) and cornu ammonis region 3 (CA3) up to ninety days after fractionated irradiation showed that proliferating cells with neuronal features resides the stratum pyramidale and neighboring layers are more susceptible to irradiation than GFAP-positive astrocytes. Regarding to distribution of astrocytes, the radiation response curve showed interesting dynamic of changes in course of experiment, however, nonsignificant results have been observed. Several studies reported that radiation cause activation of astrocytes (reactive gliosis) and microglial cells at least 6 months after fractionated treatment (Mildenberger et al. 1990; Cicciarello et al. 1996; Yuan et al. 2006). Although radiation-induced gliosis is not direct indicator of inflammation, it is associated with brain inflammation. Irradiated microglia induces the activation of astrocytes through the release of prostaglandin E2 (PGE2) which is found elevated in brain following injury (Hwang et al. 2006). According to findings obtained from both brains regions and results obtained on a similar topic from other laboratories (Shinohara et al. 1997; Tada et al. 1999; Mizumatsu et al. 2003; Yuan et al. 2006) we can speculated, that observed changes seems to be associated rather with temporary neuroprotective response of glial cells than late radiation-induced effects resulting in reactive gliosis.

We may summarise that proliferative Ki-67 labeled cells arisen from SVZa during their migration from the caudal to the rostral part of the RMS they die, cease to proliferate or accumulate in the caudal parts of the RMS due to slackening of migration. However, low level of apoptosis in course of experiment is partly in accordance with findings of Uberti et al. (2001) who revealed a similar response in mouse dentate gyrus characterized by an early inhibition and delayed stimulation of cell proliferation. Morever, apparent predominance of apoptosis in the most rostral region may suggest delayed effect of fractionated irradiation. On the other hand, overdistribution of astrocytes in a site of lesion or adjacent to area of radiation lesion raises the question about mechanisms which are involved in origination of such conspicuous astrocytic response. Given the recently reported evidence about continuing neurogenesis in adult human forebrain (Curtis et al. 2007), the observation that the progenitor cells are highly sensitive to radiation-induced apoptosis may have implications for radiotherapy. Further research should clarify whether depletion of progenitors from the SVZ could contribute to complications of therapeutic brain irradiation.

Acknowledgements. The authors are grateful to colleagues from Department of Radiotherapy and Oncology of Martin University Hospital for technical assistance with irradiation. We would like to express our thanks to Dr. M. Martončíková for drawing scheme of sagittal view of the rat forebrain, Dr. M. Kovalská for providing caspase3 antibody, Mrs. M. Kondeková, Mrs. A. Rešetárová and Mrs. Z. Cetlová for their excellent technical assistance. This work was supported by a VEGA grant 1/0050/11 and project "Center of Excellency for Research in Personalized Therapy (CEVYPET)", code: 26220120053 and "Identification of novel markers in the diagnostic panel of neurological diseases" co-financed from EU sources and European Regional Development Fund.

Conflict of interest: The authors declared no conflict of interest in relation to the article.

\section{References}

Abrous D. N., Koehl M., Le Moal M. (2005): Adult neurogenesis: from precursors to network and physiology. Physiol. Rev. 85, 523-569 http://dx.doi.org/10.1152/physrev.00055.2003

Amano T., Inamura T., Wu C. M., Kura S., Nakamizo A., Inoha S., Miyazono M., Ikezaki K. (2002): Effects of single low dose irradiation on subventricular zone cells in juvenile brain. Neurol. Res. 24, 809-816

http://dx.doi.org/10.1179/01616410

Bálentová S., Račeková E., Martončíková M., Mišúrová E. (2006): Cell proliferation in the adult rat rostral migratory stream following exposure to gamma irradiation. Cell. Mol. Neurobiol. 26, 1129-1137 http://dx.doi.org/10.1007/s10571-006-9067-3

Bálentová S., Račeková E., Mišúrová E. (2007): Effect of low dose irradiation on proliferation dynamics in the rostral migratory stream of adult rats. Folia Biol. (Prague) 53, 74-78

Bálentová S., Slovinská L., Mišúrová E., Rybárová S., Adamkov M. (2008): Effect of paternal rat irradiation transmitted to the progeny during prenatal development. Folia Biol. (Prague) 54, 151-156

Bálentová S., Hajtmanová E., Mellová Y., Bošelová L., Fuseková E., Ochodnická E., Adamkov M. (2011): Alterations in the rat 
forebrain apoptosis following exposure to ionizing radiation. Biologia 66, 701-705 http://dx.doi.org/10.2478/s11756-011-0068-4

Bálentová S., Hajtmanová E., Kinclová, I., Lehotský, J., Dobrota, D., Adamkov M. (2012): Radiation-induced long-term alterations in hippocampus under experimental conditions. Klin. Onkol. 25, 110-116

Biebel M., Cooper C. M., Winkler J., Kuhn H. G. (2000): Analysis of neurogenesis and programmed cell death reveals a self-renewing capacity in the adult brain. Neurosci. Lett. 291, 17-20 http://dx.doi.org/10.1016/S0304-3940(00)01368-9

Brunjes P. C., Armstrong A. M. (1996): Apoptosis in the rostral migratory stream of the developing rat. Dev. Brain Res. 92, 219-222 http://dx.doi.org/10.1016/0165-3806(96)00006-5

Carleton A., Petreanu L. T., Lansford R., Alvarez-Buylla A., Lledo P. M. (2003): Becoming a new neuron in the adult olfactory bulb. Nat. Neurosci. 5, 507-518

Cicciarello R., d'Avella D., Gagliardi M. E., Albiero F., Vega J., Angileri F. F., D‘Aquino A., Tomassello F. (1996): Time-related ultrastructural changes in an experimental model of whole brain irradiation. Neurosurgery $\mathbf{3 8}, 772-779$ http://dx.doi.org/10.1227/00006123-199604000-00028

Curtis M. A., Kam M., Nannmark U., Anderson M. F., Axell M. Z., Wikkelso C., Holtas S., van Roon-Mom W. M., BjorkEriksson T., Nordborg C., Frisen J. F., Dragunow M., Faull R. L., Eriksson P. S. (2007): Human neuroblasts migrate to the olfactory bulb via a lateral ventricular extension. Science $315,1243-1249$ http://dx.doi.org/10.1126/science.1136281

Doetsch F., García-Verdugo J. M., Alvarez-Buylla A. (1997): Cellular composition and three-dimensional organisation of the subventricular germinal zone in the adult mammalian brain. J. Neurosci. 17, 5046-5061

Dubrova Y. E., Plumb M., Brown J., Jeffreys A. J. (1998): Radiationinduced germline instability at minisatellite loci. Int. J. Radiat. Biol. 74, 689-696 http://dx.doi.org/10.1080/095530098140952

Gaber M. W., Sabek O. M., Fukatsu K., Wilcox H. G., Kiani M. F., Merchant T. E. (2003): The differences in ICAM-1 and TNF- $\alpha$ expression between high single fractions and fractionated irradiation in mouse brain. Int. J. Radiat. Biol. 79, 359-366 http://dx.doi.org/10.1080/0955300031000114738

Hwang S. Y., Jung J. S., Kim T. H., Lim S. J., Oh E. S., Kim J. Y., Ji K. A., Joe E. H., Cho K. H., Han I. O. (2006): Ionizing radiation induces astrocyte gliosis through microglia activation. Neurobiol. Dis. 21, 457-467 http://dx.doi.org/10.1016/j.nbd.2005.08.006

Chow B. M., Li Y. Q.,Wong C. S. (2000): Radiation-induced apoptosis in the central nervous system is p53-dependent. Cell Death Differ. 7, 712-720 http://dx.doi.org/10.1038/sj.cdd.4400704

Kamiryo T., Kassell N. F., Thai Q. A., Lopes M. B. S., Lee K. S., Steiner L. (2005): Histological changes in the normal rat brain after gamma irradiation. Acta Neurochir. (Wien) 138, 451-459 http://dx.doi.org/10.1007/BF01420308

Kempermann G. (2002): Why new neurons? Possible functions for adult hippocampal neurogenesis. J. Neurosci. 22, 635-638
Kurita H., Kawahara N., Asai A., Ueki K., Shin M., Kirino T. (2001): Radiation-induced apoptosis of oligodendrocytes in the adult rat brain. Neurol. Res. 23, 869-874 http://dx.doi.org/10.1179/016164101101199324

Lazarini F., Mouthon M. A., Gheusi G., de Chaumont F., OlivoMarin J. C., Lamarque S., Abrous D. N., Boussin F. D., Lledo P. M. (2009): Cellular and behavioral effects of cranial irradiation of the subventricular zone in adult mice. PLoS One 4, e7017 http://dx.doi.org/10.1371/journal.pone.0007017

Lledo P. M., Alonso M., Grubb M. S. (2006): Adult neurogenesis and functional plasticity in neuronal circuits. Nat. Rev. Neurosci. 7, 179-193 http://dx.doi.org/10.1038/nrn1867

Little J. B. (2000): Radiation carcinogenesis. Carcinogenesis. 21, $397-404$ http://dx.doi.org/10.1093/carcin/21.3.397

Mildenberger M., Beach T. G., McGeer E. G., Ludgate C. M. (1990): An animal model of prophylactic cranial irradiation: Histologic effects at acute, early and delayed stages. Int. J. Radiat. Oncol. Biol. Phys. 18, 1051-1060 http://dx.doi.org/10.1016/0360-3016(90)90440-U

Mizumatsu S., Monje L. M., Morhardt D. R., Rola R., Palmer T. D., Fike J. R. (2003) Extreme sensitivity of adult neurogenesis to low doses of X-irradiation. Cancer Res. 63, 4021-4027

Münter M. W., Karger C. H., Reith W., Schneider M. H., Peschke P., Debus J. (1999): Delayed vascular injury after single high-dose irradiation in the rat brain: histologic immunohistochemical, and angiographic studies. Radiology 212, 475-482

Peissner W., Kocher M., Treuer H., Gillardon F. (1999): Ionizing radiation-induced apoptosis of proliferating stem cells in the dentate gyrus of the adult rat hippocampus. Mol. Brain Res. $71,61-68$ http://dx.doi.org/10.1016/S0169-328X(99)00170-9

Sano K., Sato M., Tanaka R. (1997): Radiation-induced apoptosis and injury of oligodendrocytes on neonatal rat brains. Clin. Neurol. Neurosur. 99 (Suppl. 1), S117 http://dx.doi.org/10.1016/S0303-8467(97)81791-X

Shinohara C., Gobbel G. T., Lamborn K. R., Tada E., Fike J. R. (1997): Apoptosis in the subependyma of young adult rats after single and fractionated doses of X-rays. Cancer Res. 57, 2694-2702

Smith L. E., Nagar S., Kim G. J., Morgan W. F. (2003): Radiation-induced genome instability: radiation quality and dose response. Health Phys. 85, 23-29 http://dx.doi.org/10.1097/00004032-200307000-00006

Snyder J. S., Hong N., McDonald R. J., Wojtowicz J. M. (2005): A role for adult hippocampal neurogenesis in spatial long-term memory. Neuroscience 130, 843-852

http://dx.doi.org/10.1016/j.neuroscience.2004.10.009

Sundholm-Peters N. L., Yang H. K., Goings G. E., Walker A. S., Szele F. G. (2005): Subventricular zone neuroblasts emigrate toward cortical lesions. J. Neuropathol. Exp. Neurol. 64, 1089-1100 http://dx.doi.org/10.1097/01.jnen.0000190066.13312.8f

Tada E., Yang C., Gobbel G. T., Lamborn K. R., Fike J. R. (1999): Long-term impairment of subependymal repopulation following damage by ionizing radiation. Exp. Neurol. 160, 66-77 
http://dx.doi.org/10.1006/exnr.1999.7172

Thomaidou D., Mione M. C., Cavanagh J. F., Parnavelas J. G. (1997): Apoptosis and its relation to the cell cycle in the developing cerebral cortex. J. Neurosci. 17, 1075-1085

Uberti D., Piccioni L., Cadei M., Grigolato P., Rotter V., Memo M. (2001): P53 is dispensable for apoptosis but controls neurogenesis of mouse dentate gyrus cells following gamma-irradiation. Brain Res. Mol. Brain Res. 93, 81-89 http://dx.doi.org/10.1016/S0169-328X(01)00180-2

Vasilyeva G. V., Bezlepkin V. G., Lomaeva M. G., Sirota N. P., Gaziev A. I. (2001): AP-PCR assay of DNA alterations in the progeny of male mice exposed to low-level gamma-radiation. Mutat. Res. 488, 133-141
Wong C. S., Van der Kogel A. J. (2004): Mechanisms of radiation injury to the central nervous system: implications for neuroprotection. Mol. Interv. 4, 273-284 http://dx.doi.org/10.1124/mi.4.5.7

Yuan H., Gaber M. W., Boyd K., Wilson C. M., Kiani M. F., Merchant T. E. (2006): Effects of fractionated radiation on the brain vasculature in a murine model: blood-brain barrier permeability, astrocyte proliferation, and ultrastructural changes. Int. J. Radiat. Oncol. Biol. Phys. 66, 860-866

http://dx.doi.org/10.1016/j.ijrobp.2006.06.043

Received: December 6, 2011

Final version accepted: June 20, 2012 